\title{
Silica nanoparticles with encapsulated DNA (SPED) to trace the spread of pathogens in healthcare
}

Cinzia Ullrich ${ }^{1 \dagger}$, Anne M. Luescher ${ }^{2 \dagger}$, Julian Koch ${ }^{2}$, Robert N. Grass ${ }^{2^{*+}}$ and Hugo Sax ${ }^{1,3^{*+}}$ (1)

\begin{abstract}
Background: To establish effective infection control protocols, understanding pathogen transmission pathways is essential. Non-infectious surrogate tracers may safely explore these pathways and challenge pre-existing assumptions. We used silica nanoparticles with encapsulated DNA (SPED) for the first time in a real-life hospital setting to investigate potential transmission routes of vancomycin-resistant enterococci in the context of a prolonged outbreak.

Methods: The two study experiments took place in the 900-bed University Hospital Zurich, Switzerland. A three-run 'Patient experiment' investigated pathogen transmission via toilet seats in a two-patient room with shared bathroom. First, various predetermined body and fomite sites in a two-bed patient room were probed at baseline. Then, after the first patient was contaminated with SPED at the subgluteal region, both patients sequentially performed a toilet routine. All sites were consequently swabbed again for SPED contamination. Eight hours later, further spread was tested at predefined sites in the patient room and throughout the ward. A two-run 'Mobile device experiment' explored the potential transmission by mobile phones and stethoscopes in a quasi-realistic setting. All SPED contamination statuses and levels were determined by real-time qPCR.

Results: Over all three runs, the 'Patient experiment'yielded SPED in 59 of 73 (80.8\%) predefined body and environmental sites. Specifically, positivity rates were $100 \%$ on subgluteal skin, toilet seats, tap handles, and entertainment devices, the initially contaminated patients' hands; $83.3 \%$ on patient phones and bed controls; $80 \%$ on intravenous pumps; $75 \%$ on toilet flush plates and door handles, and $0 \%$ on the initially not contaminated patients' hands. SPED spread as far as doctor's keyboards (66.6\%), staff mobile phones (33.3\%) and nurses' keyboards (33.3\%) after eight hours. The 'Mobile device experiment' resulted in 16 of 22 (72.7\%) positive follow-up samples, and transmission to the second patient occurred in one of the two runs.
\end{abstract}

*Correspondence: robert.grass@chem.ethz.ch; hugo.sax@mac.com

${ }^{\dagger}$ Cinzia Ullrich and Anne M. Luescher contributed equally to this article as

first authors

${ }^{\dagger}$ Robert N. Grass and Hugo Sax contributed equally to this article as last

authors

${ }^{2}$ Department of Chemistry and Applied Biosciences, Institute

for Chemical and Bioengineering, ETH Zurich, Vladimir-Prelog-Weg

1-5/10, 8093 Zurich, Switzerland

${ }^{3}$ Department of Infectious Diseases, Bern University Hospital and University of Bern, Friedbuehlstrasse 53, 3010 Bern, Switzerland

Full list of author information is available at the end of the article

(c) The Author(s) 2021. Open Access This article is licensed under a Creative Commons Attribution 4.0 International License, which permits use, sharing, adaptation, distribution and reproduction in any medium or format, as long as you give appropriate credit to the original author(s) and the source, provide a link to the Creative Commons licence, and indicate if changes were made. The images or other third party material in this article are included in the article's Creative Commons licence, unless indicated otherwise in a credit line to the material. If material is not included in the article's Creative Commons licence and your intended use is not permitted by statutory regulation or exceeds the permitted use, you will need to obtain permission directly from the copyright holder. To view a copy of this licence, visit http://creativecommons.org/licenses/by/4.0/. The Creative Commons Public Domain Dedication waiver (http://creativeco mmons.org/publicdomain/zero/1.0/) applies to the data made available in this article, unless otherwise stated in a credit line to the data. 
Conclusions: For the first time SPED were used to investigate potential transmission pathways in a real hospital setting. The results suggest that, in the absence of targeted cleaning, toilet seats and mobile devices may result in widespread transmission of pathogens departing from one contaminated patient skin region.

Keywords: Infection control, Infection prevention, Pathogen transmission, Silica nanoparticles, Surrogate markers

\section{Background}

Healthcare associated infections (HCAI) cause higher complication and mortality rates, prolonged hospital stays, and increased healthcare costs $[1,2]$. Moreover, the spread of antimicrobial resistant pathogens is considered one of the most crucial issues in healthcare [3].

Multiple large-scale outbreaks of vancomycin-resistant enterococci (VRE) in Swiss hospitals in the last decade indicate a surge of VRE in Switzerland [4-6]. Poor hand hygiene $(\mathrm{HH})$ has proven to be a primary cause of pathogen transmission [7]. Guidelines and protocols have been established to improve hand hygiene in healthcare $[2,8]$ with limited overall success $[9,10]$. Several studies published over the past 20 years indicate the effect of contaminated hospital environment on pathogen transmission-especially multi-resistant pathogens such as VRE [11-14]. Pittet et al. [7] list "organisms shed onto inanimate objects immediately surrounding the patient" as the starting point of cross-transmission between patients. Other studies suggest that the risk for VRE acquisition is higher when a patient stays in a hospital room previously occupied by a VRE-infected patient [15-17]. Lower rates of multi-drug resistant pathogen colonization and infection occur in hospitals with singlerooms and thus, individualized toilet use $[18,19]$.

Touching a VRE-contaminated surface carries a similar risk for pathogen-transmission on hands as touching a colonized patient even though the concentration of VRE on surfaces is much lower [12, 20, 21]. Randle et al. [22] found that $\mathrm{HH}$ compliance in $\mathrm{HCW}$ was $80 \%$ [adjusted odds ratio (aOR) 1.88, 95\% CI 1.15-3.07)] after direct patient contact, whereas $\mathrm{HH}$ was performed in only $50 \%$ (aOR $0.60,95 \%$ CI $0.38-0.93$ ) after contact with a patient's surroundings. In an observational study with head cameras during real-life active patient care Clack et al. even found a $\mathrm{HH}$ "adherence" of only $5 \%$ prior to potentially patient colonizing touch events and only $1 \%$ before possible infection events (e.g., before touching central line insertion sites, wounds, sterile needles) [10].

It is not surprising that Cassone et al. [23] included toilet seats in an environmental panel as a proxy for patients with VRE colonization. Although many experts emphasize the transmission of pathogens from contaminated areas through the hands of healthcare workers (HCW), fewer recognize the effect of shared bathrooms or toilets as possible transmission hubs of multi-drug resistant microorganisms [24]. The transmission pathway of pathogens, in particular VRE, through toilet seats has not yet been explicitly investigated.

The use of surrogate tracers allows to safely determine patient-to-patient-transmission of pathogens in real-life care-settings [25, 26]. In the past, various pathogen surrogates have been used, including cauliflower mosaic virus DNA [27-31], bacteriophage MS-2 [29, 32, 33], non-toxigenic Clostridioides difficile spores [34], fluorescent agents [35], and light-reflecting chemical compounds combined with flashlight photography [33]. Silica nanoparticles with encapsulated DNA (SPED) with known nucleotide sequences have been described by Paunescu et al. [36] (Fig. 6). They are used as inert tracers in biological product tagging, tracing of food, studying animal predator-prey-relationships, and characterizing aquifer and wastewater [37-40]. As Scotoni et al. [25] have shown in a microbiology and a behaviour laboratory setting, that SPED represent promising surrogate tracers for microbial transmission in healthcare because SPED and bacteria share strong similarities in transmission, are non-toxic, and can be individually tagged [41].

In the current work, we aimed to investigate the spread of SPED as surrogates for pathogen transmission between patients in a real-world-scenario, involving the shared use of the toilet in a two-bed patient room. As SPED are insensitive to common disinfectants this study aims to display transmission pathways in an environment without disinfection procedures. This investigation was clinically motivated by an ongoing VRE outbreak in our hospital in the course of which the risk of shared restroom use and necessary cleaning schedules became a topic of interest.

\section{Methods \\ SPED and swab technique}

The synthesis and characterization of SPED followed the protocol of Paunescu et al. [36]. We used the same three batches of SPED with individual DNAtagging as previously described by Scotoni et al. [25], SPED-1 (218 $\pm 80 \mathrm{~nm}$; DNA loading $21 \mu \mathrm{g})$, SPED-2 $(146.6 \pm 46 \mathrm{~nm}$; DNA loading $23 \mu \mathrm{g})$, and SPED-3 $(173.4 \pm 82 \mathrm{~nm}$; DNA loading $26 \mu \mathrm{g})$. The nature and handling of SPED is described in detail in the Technical Appendix. 


\section{Quantification of SPED and statistical analysis}

The procurance of exact SPED concentration levels based on real-time quantitative PCR (qPCR) cycle values is specified in the Technical Appendix. Before deposition of SPED every swabbing site was swabbed as baseline sample. To evaluate the corresponding concentrations in $\mathrm{mg} / \mathrm{mL}$, all samples were compared with an experimentspecific threshold resulting from the SPED concentration of the baseline sample yielding the strongest qPCR signal and thus, the highest concentration of all baseline samples. This represents a conservative approach to adjust all results for background signals resulting from contamination arising during experimental processing. Consequently, values with concentrations above threshold were considered as positive, values below as negative. The descriptive analysis was conducted with Microsoft Excel ${ }^{\circledR}$ 2020 .

\section{Explorative experiments}

Before their use with patients, we chose to explore SPED for transmission characteristics in relation to the necessary amount and concentration in the restroom of an office building of the hospital campus in two controlled experiments.

First, $3 \mathrm{~mL}$ of a $1 \mathrm{mg} / \mathrm{mL}$ SPED suspension in ultrapure MilliQ water (type $1,18.2 \mathrm{M} \Omega \cdot \mathrm{cm}$ at $24{ }^{\circ} \mathrm{C}$, Milli- $Q^{\circledR}$; Merck, Darmstadt, Germany) were deposited on bare skin at a subgluteal skin site of a voluntary 27 -year-old male participant and left to air-dry. The participant was then asked to sit on the toilet seat for ten seconds, flush the toilet, and perform handwashing after having left the restroom by using the door handle. The participant's contaminated body site, toilet seat, toilet flush plate, door handle, and tap were swabbed before and after this sequence. In a follow-up experiment, we verified the transmission of SPED from a Participant-A, contaminated equally as described above, to Participant- $B$, both subsequentially performing the same toilet use sequence as described above.

\section{Patient experiment}

The patient experiment took place in patient rooms on a haemato-oncological ward at the University Hospital Zurich, Switzerland, it was repeated three times (Run-1Run-3) with a new SPED batch being used (SPED-1SPED-3) for each run. Run-1 and Run-2 took place in the same, Run-3 in another patient room of similar layout (Fig. 1). During the experiment, cleaning in the patient room was limited to floor wiping.

Any pair of patients in a two-bed room were eligible for the study if they both gave informed consent. They were conveniently chosen by ward staff and allowed to withdraw at any time without indicating a reason. The ward staff was collectively informed about the study with the possibility to opt out.

We pre-defined 20 swabbing sites dimensioned $1 \times 3 \mathrm{~cm}, 16$ concerning fomites, of which eight were located inside, four in the restroom and four outside the patient room, and two body sites on each patient (Table 1). These swab sites were chosen following the idea of 'high-touch surfaces' according to Huslage et al. [42]. Swabbing was performed as described in the "Technical Appendix".

First, all sites were swabbed as negative controls. Then, we applied $3 \mathrm{~mL}$ of our SPED test suspension $(1 \mathrm{mg} / \mathrm{mL})$ to the subgluteal region of Patient-A by using a graduated pipette and a brush and left it to air-dry. A swab from the subgluteal swabbing sites of Patient-A taken immediately after contamination constituted the positive control. Consecutively, we asked Patient-A to dress, go to the bathroom and sit on the toilet seat for $10 \mathrm{~s}$. Then PatientA would dress, flush the toilet, perform handwashing with soap and water, open the bathroom door and go back to bed. While performing this toilet sequence Patient-A was not observed, leaving it therefore open whether Patient A touched the toilet ring, his/her own subgluteal region or no fomite at all. Immediately after this sequence, we took swabs of Patient-A's subgluteal skin as well as from the toilet seat, tap handle, flush plate, and bathroom door handle. Subsequently, Patient-B was asked to perform the same toilet use sequence as PatientA. We again took samples from the predefined Patient-B and environmental swabbing sites. Then, the researcher left the ward asking both patients to behave as usual.

After an eight-hour interval, the researcher returned to the ward and sampled both patients' hands and three predefined environmental sites for each patient (i.e., bed control unit, phone, the personal entertainment device that the patient reported to have mainly used among laptop, e-reader, tablet, hospital-bedside TV, and intravenous pump). Keyboards and mobile phones of the nurse and the physician intern in charge of Patient- $A$ and Patient-B were swabbed accordingly (Table 1). No decontamination process was applied after the SPED experiments.

\section{Mobile device experiment}

To investigate whether SPED transmit from one patient to another through HCW mobile phones, we conceived an additional quasi-realistic experiment with the help of healthy volunteers.

Four volunteers performed a standardized scenario as Patient- $\mathrm{A}^{\prime}$, Patient- $\mathrm{B}^{\prime}$, Doctor- $\mathrm{A}$, and Doctor-B in a simulated two-bed hospital room involving personal stethoscopes and a single shared mobile phone (Fig. 2), 

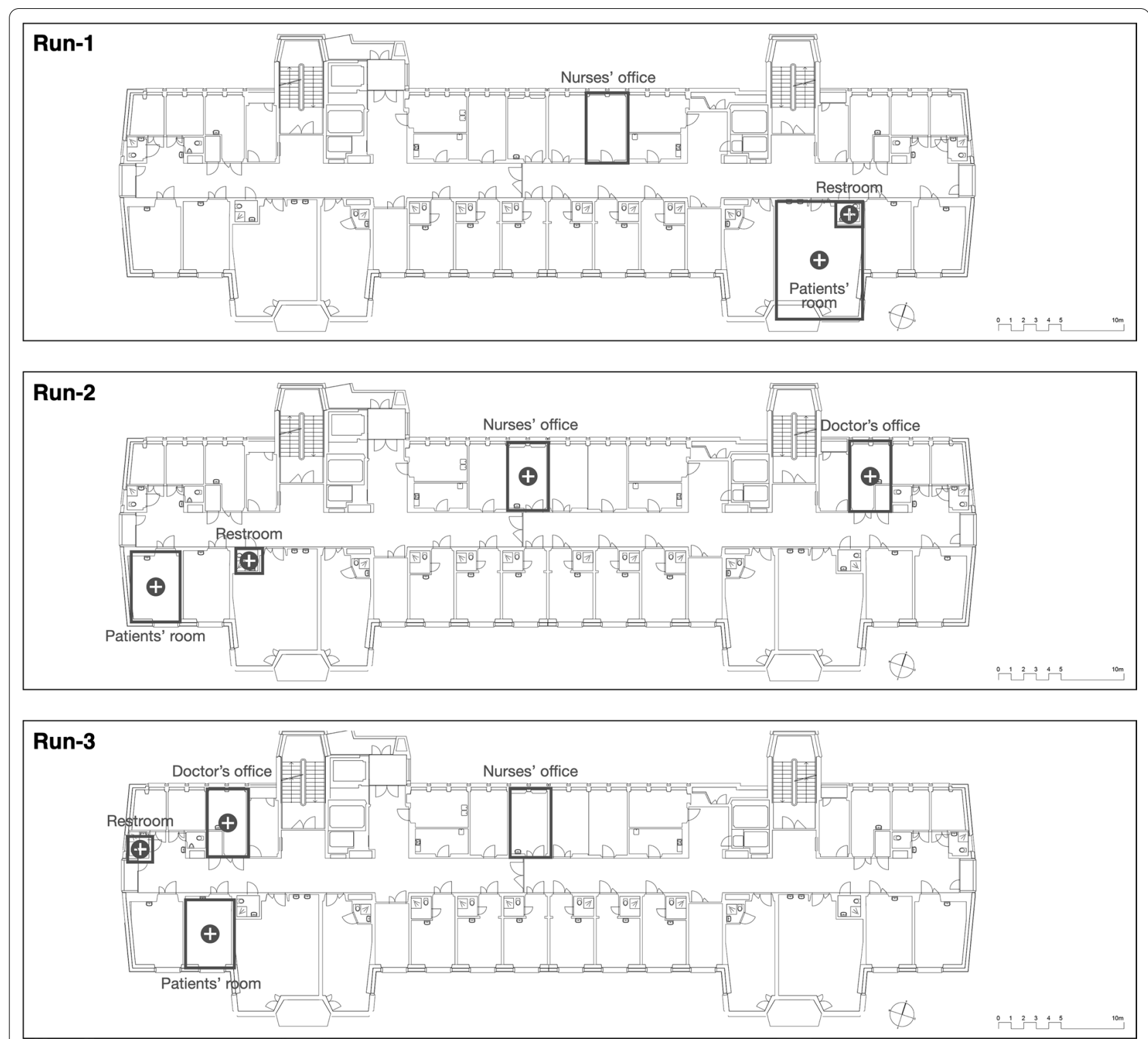

Fig. 1 Floor plan of the 'Patient experiment' ward with room assignments. The floorplan shows the study ward three times (once for each study run) and the localisation of the two-bed patient room, shared restroom, nurses' and doctor's office in the study ward. In Run-1 the doctor's office was situated on another floor and does therefore not appear in the floor plan. The plus signs indicate rooms with one or more positive SPED swabbing results at 8-h follow-up. Detailed swabbing sites s. Table 1. SPED silica nanoparticles with encapsulated DNA

repeated as Run-1' and Run-2' using SPED-3 and SPED-2, respectively. SPED were deployed on PatientA's wrist, chest, and neck. Then, Doctor-A examined Patient- $\mathrm{A}^{\prime}$, answered the mobile phone, which was consequently used by Doctor- $B$, who in turn examined Patient- $\mathrm{B}^{\prime}$. Before SPED deployment and after, the experiment swabs were taken from the patients' wrists, neck and chest, both doctors' hands and cheeks, and both stethoscopes as well as the front and back of the mobile phone (Table 2).

\section{Results}

Explorative experiments

Both explorative experiments successfully established transmission signals with the applied SPED amount and concentration from human skin to inanimate surfaces and back to skin (Fig. 3).

After testing different cleaning processes, we found a thorough cleaning process using water and a household detergent (Oekoplan, Coop) with multiple applications ( $\geq 5$ times) each time using a new paper tissue 
Table 1 Swabbing sites in the 'Patient experiment'for all three runs

\begin{tabular}{|c|c|c|c|}
\hline & $\begin{array}{l}\text { Sampling sites before deployment of } \\
\text { SPED at baseline }\end{array}$ & $\begin{array}{l}\text { Sampling sites immediately after } \\
\text { toilet sequence }\end{array}$ & $\begin{array}{l}\text { Sampling sites after } \\
\text { eight-hour interval }\end{array}$ \\
\hline \multicolumn{4}{|l|}{ Patient skin } \\
\hline Subgluteal skin patient A & $x$ & $x$ & \\
\hline Hands/palms patient A & $x$ & & $x$ \\
\hline Subgluteal skin patient B & $x$ & $x$ & \\
\hline Hands/palms patient B & $x$ & & $x$ \\
\hline \multicolumn{4}{|l|}{ Restroom } \\
\hline Toilet seat after patient $A$ & $x$ & $x$ & \\
\hline Flush plate after patient A & $x$ & $x$ & \\
\hline Tap handle after patient A & $x$ & $x$ & \\
\hline Door handle after patient A & $x$ & $x$ & \\
\hline Toilet seat after patient B & $x$ & $x$ & \\
\hline Flush plate after patient B & $x$ & $x$ & \\
\hline Tap handle after patient B & $x$ & $x$ & \\
\hline Door handle after patient $B$ & $x$ & $x$ & \\
\hline \multicolumn{4}{|l|}{ Patient room } \\
\hline Bed control patient A & $x$ & & $x$ \\
\hline Private phone patient $A^{*}$ & $x$ & & $x$ \\
\hline Entertainment device patient A† & $x$ & & $x$ \\
\hline Intravenous pump patient A & $x$ & & $x$ \\
\hline Bed control patient B & $x$ & & $x$ \\
\hline Private phone patient $\mathrm{B}^{*}$ & $x$ & & $x$ \\
\hline Entertainment device patient $\mathrm{B}+$ & $x$ & & $x$ \\
\hline Intravenous pump patient B & $x$ & & $x$ \\
\hline \multicolumn{4}{|l|}{ Nurse's office } \\
\hline Nurse's mobile phone & $x$ & & $x$ \\
\hline Nurse's office keyboard & $x$ & & $x$ \\
\hline \multicolumn{4}{|l|}{ Doctor's office } \\
\hline Doctor's mobile phone & $x$ & & $x$ \\
\hline Doctor's office Keyboard & $x$ & & $x$ \\
\hline
\end{tabular}

SPED silica nanoparticles with encapsulated DNA

*The patients' private mobile phone was swapped if available, otherwise the beside phone provided by hospital

${ }^{\dagger}$ The most used device was assessed (among tablet, e-reader, laptop, hospital bedside TV): Run 1 A: tablet, B: bedside hospital TV; Run 2 A: e-reader, B: bedside hospital TV; Run 3 A: tablet, B: bedside hospital TV

eliminating SPED (Fig. 3). During all cleaning procedures gloves were worn to avoid recontamination. Microfiber cloths were not suitable to eliminate SPED.

\section{Patient experiment}

Overall, 133 swabs were collected during Run-1 to Run-3. The highest concentrations for 60 negative control samples before SPED deployment for Run-1, Run-2, and Run-3 were $3.01 \times 10^{-08} \mathrm{mg} / \mathrm{mL}$ (SPED 3), $9.55 \times 10^{-09} \mathrm{mg} / \mathrm{mL}$ (SPED 2) and $8.21 \times 10^{-09} \mathrm{mg} / \mathrm{mL}$ (SPED-1), respectively, serving as run-specific positivity thresholds. Of the remaining 73 samples, 59 (80.8\%) were positive (Fig. 4). Although the recovered SPED followed the logic of reduced concentrations with multiple touching sequences, there were considerable quantitative differences between the runs. Over all three runs, positivity rates were $100 \%$ on subgluteal skin, toilet seats, tap handles, and entertainment device controls, Patient-A's hands; $83.3 \%$ on patient phones and bed controls; $80 \%$ on intravenous pumps; $75 \%$ on toilet flush plate and door handle, $66.6 \%$ on doctor's keyboards; and $33.3 \%$, on nurses' or doctors' phones, nurse's keyboards, and $0 \%$ on Patient-Bs' hands.

\section{Mobile device experiment}

Overall, 56 samples were collected. Positivity thresholds in 28 baseline samples were $7.36 \times 10^{-7} \mathrm{mg} / \mathrm{mL}$ (SPED-3) and $1.63 \mathrm{E} \times 10^{-7} \mathrm{mg} / \mathrm{mL}$ (SPED-2) for Run- $1^{\prime}$ 


Fig. 2 Setup of the 'Mobile device experiment'. Scenarios plot: (1) Researcher deploys SPED on neck (A. carotis), chest (Erb's point), and wrist (A.
radialis) of Patient-A'; (2) Doctor-A listens to heart sounds and takes radial pulse of Patient-A'; (3) Phone rings, Doctor-A takes the call for 30 s,
then leaves the experiment scene; (4) Phone rings again, Doctor-B takes the call for 30 s; and (5) listens to heart sounds and takes radial pulse of
Patient-B'. Star symbols indicate SPED swabbing sites. SPED silica nanoparticles with encapsulated DNA.

Table 2 Swabbing sites in the 'Mobile device experiment' for both runs

Patient $A^{\prime}$

Wrist, radial pulse point

Neck, carotid pulse point

Chest, Erb's point

Doctor A

Cheek, phone touching point

Hands, palms

Stethoscope A, chest piece

Patient $B^{\prime}$

Wrist, radial pulse point

Neck, carotid pulse point

Chest, Erb's point

Doctor $B$

Cheek, phone touching point

Hands, palms

Stethoscope B, chest piece

Mobile phone

Phone, frontside screen

Phone, backside

$\begin{array}{ll}x & x \\ x & x \\ x & x \\ x & x \\ x & x \\ x & x \\ x & \\ x & x \\ x & x \\ x & x \\ x & \\ x & x \\ x & x \\ x & x \\ & \\ x & x \\ x & x\end{array}$

SPED silica nanoparticles with encapsulated DNA

and Run-2', respectively. The baseline sample of Doctor-A's hands in Run-1' was accidently contaminated and ignored. Of the 22 post-experiment samples, not including the initial SPED deposition sites on Patient $\mathrm{A}^{\prime}, 16$ (72.7\%) tested positive for SPED (Fig. 5).

\section{Discussion}

After Scotoni et al. [25] explored SPED transmission in the laboratory and found their transmission behaviour to be similar to that of bacteria, the current study employed SPED for the first time in a real-life hospital environment. 


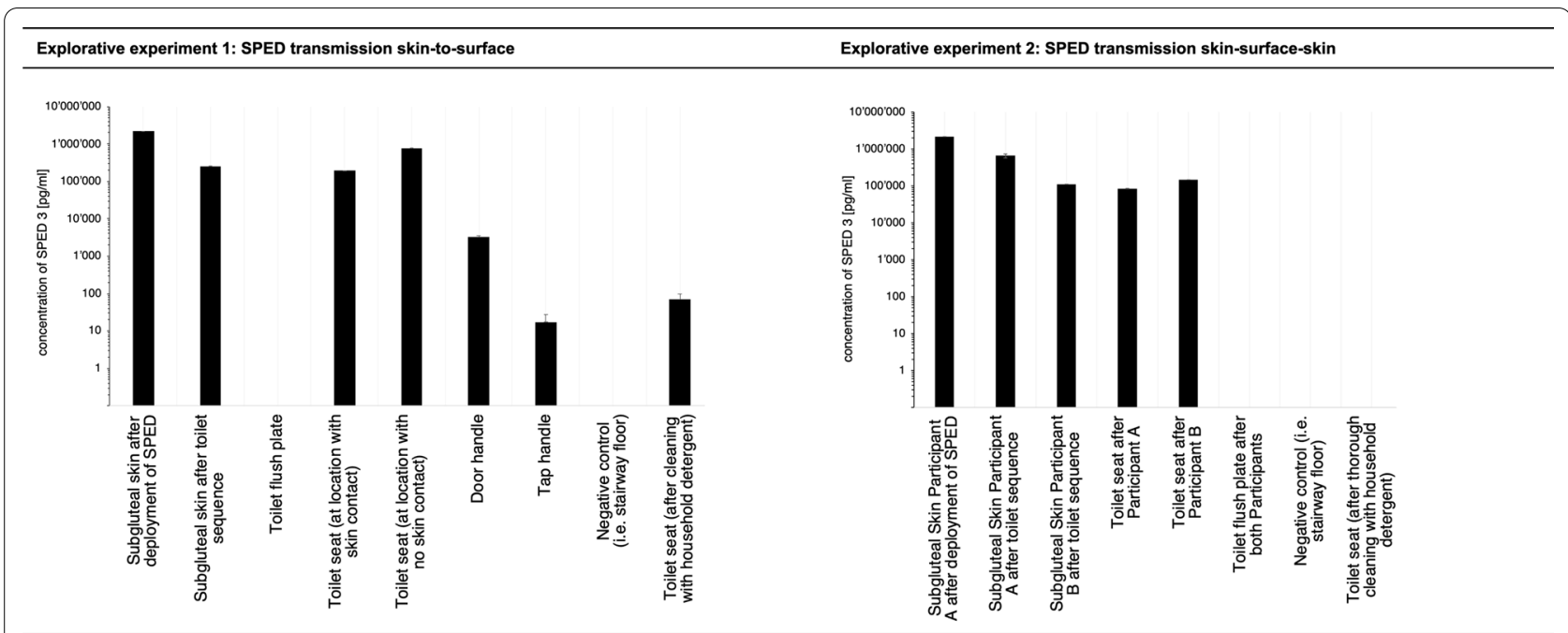

Fig. 3 Results of the 'Explorative experiments'. Explorative experiment 1: Transmission of SPED deployed to subgluteal human skin to inanimate objects such as the toilet seat or the door handle through a standardized toilet sequence; Explorative experiment 2: Transmission of SPED deployed on Participant-A's subgluteal skin to Participant-B's subgluteal region through successive use of the same toilet. The concentrations of SPED as measured by qPCR are displayed on a logarithmic scale. The baseline corresponds to the background concentration, meaning any positive value in the diagram corresponds to a signal above the baseline samples taken before SPED deployment. SPED silica nanoparticles with encapsulated DNA

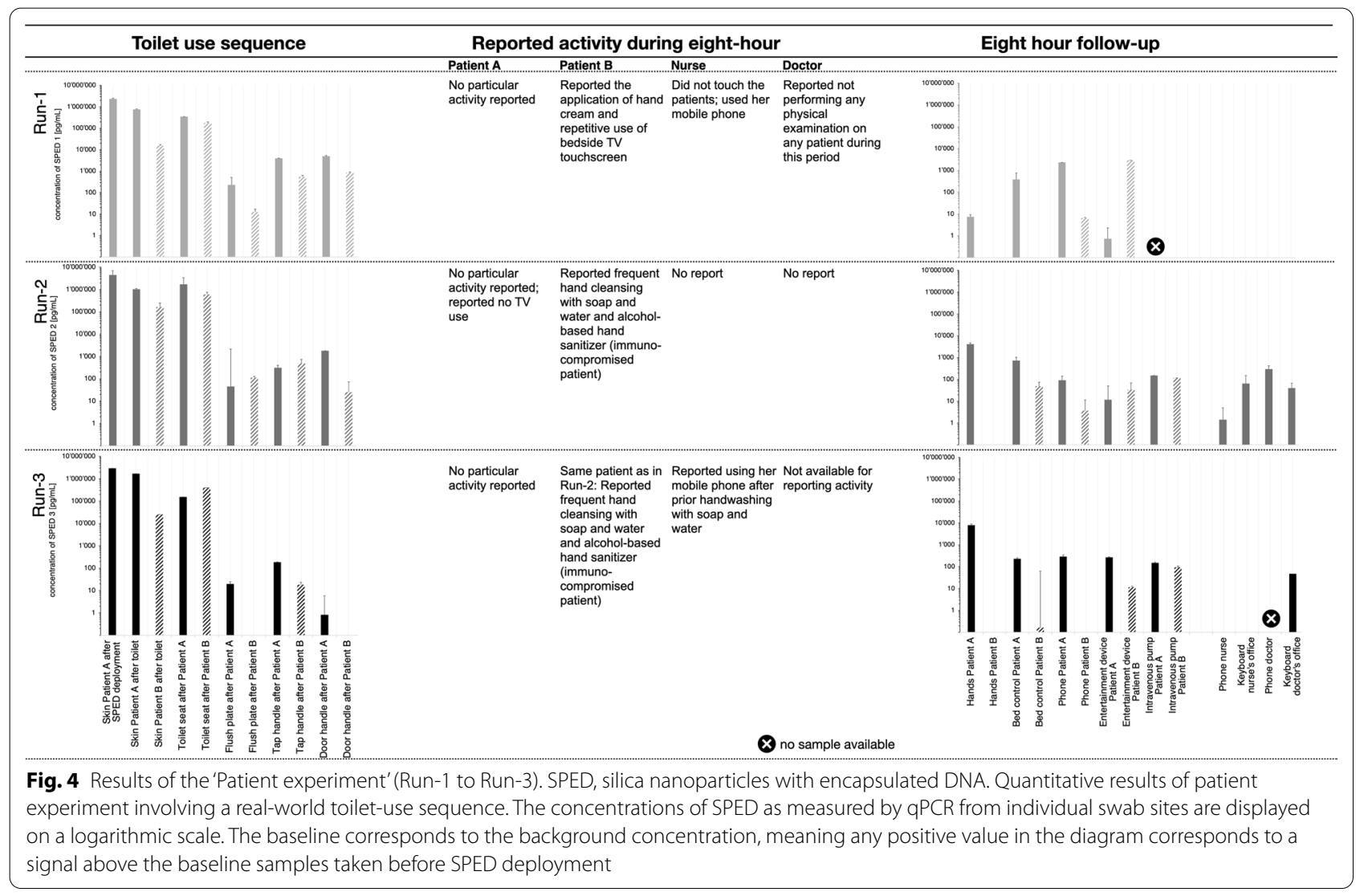




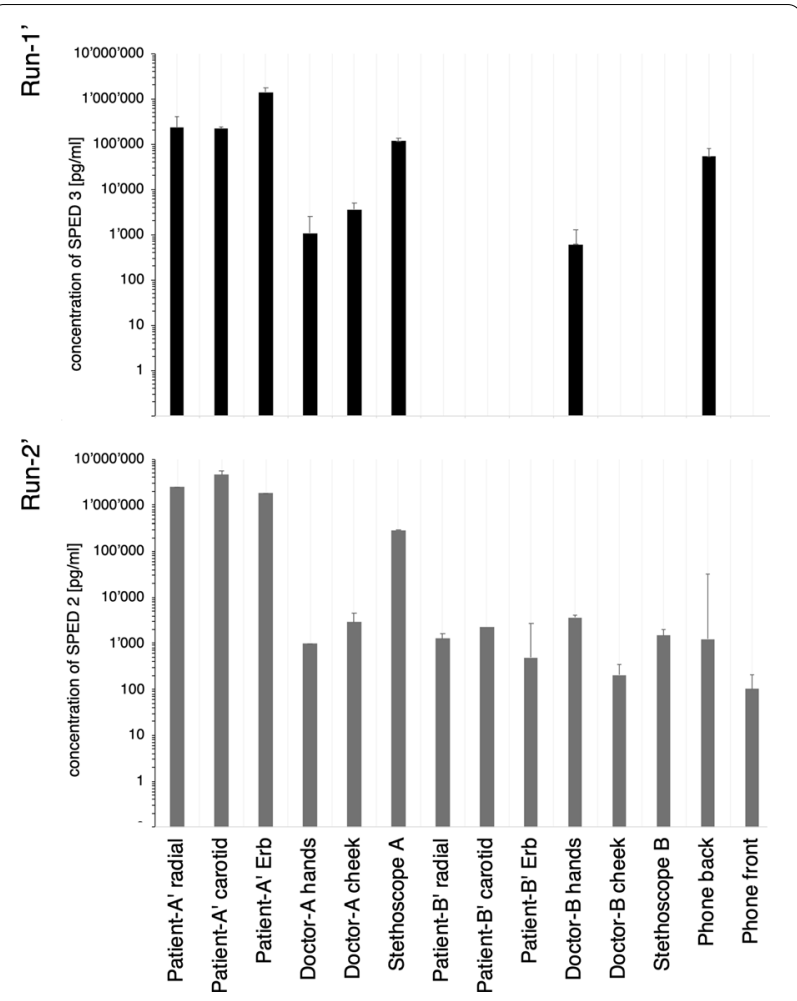

Fig. 5 Results of the 'Mobile device experiment'. Quantitative results of experiment mimicking a mobile device use scenario. The concentrations of SPED as measured by qPCR from individual swab sites are displayed on a logarithmic scale. The baseline corresponds to the background concentration, meaning any positive value in the diagram corresponds to a signal above the baseline samples taken before SPED deployment

After establishing the method of skin contamination and sampling, we found SPED transmission from one patient to another via toilet use and spread to patient surroundings as far as distant HCWs' mobile phones and keyboards consistently over all runs. An additional off-site experiment confirmed that $\mathrm{HCW}$ mobile phones indeed transmitted SPED between patients.

The patient experiment indicated SPED spreading from Patient-A's subgluteal skin region to the toilet seat and from there to the subgluteal region of the roommate Patient-B. In addition, Patient-A contaminated the toilet flush plate, tap handle, and door handle with their hands with SPED which were acquired from a contaminated body part or environmental site beforehand. Patient$B$ became contaminated on the subgluteal skin site by exposure to the toilet seat. Of note, SPED were detected on the door handle in most of the cases, even though touching of the door handle occurred after handwashing in the study scenario. This implies that SPED had not been completely removed by handwashing. This contrasts the findings of Scotoni et al. [25] who investigated handwashing under laboratory conditions, but it positively simulates insufficient handwashing after toilet usage that has frequently been reported as typical population behaviour [43].

Eight hours after initial exposure, SPED have found their way to many surfaces in the immediate surroundings of the two patients and, in some instances reached the mobile phones and keyboards of the HCWs in charge of the patients, far from their room. Although SPED were always detectable on Patient-As' hands, swabs of PatientBs' hands were consistently negative. Nevertheless, SPED were found on all entertainment devices swabbed during the experiment, indicating a relevant but transient contamination of the patient's hands. Swabs of Patient-A's bed position controls, phones, entertainment devices, and intravenous pumps were uniformly positive, as were most swabs of Patient-Bs' bed position controls, phones, and intravenous pumps. Patient-B tended to show lower SPED levels than Patient-A, consistent with the logic of a dilution effect over propagated spreading along a multitouch transmission pathway (Fig. 4). The lower SPED concentration found on flush plates could be explained by an uneven distribution of SPED over the hands and the way toilet handles were touched, as shown by Scotoni et al. before [25].

Intravenous pumps, which are typically only operated by nurses, showed a positive signal for SPED in $80 \%$. This echoes the findings by Huslage et al. [42], who considered these devices as "high-touch" surfaces and implied HCW hands as transmission hubs. Alternatively, but less likely, patients touched their intravenous pump themselves.

Pathogens found on toilet seats are often of faecal or skin origin including Escherichia coli, vancomycinesusceptible enterococci, VRE, and methicillin-resistant Staphylococcus aureus (MRSA) [44, 45]. Toilet seats have been suspected as culprits for VRE transmission [23] and individually attributed toilets have been associated with the control of VRE outbreaks [46, 47]. Transmission via toilet seats was, however, never formally investigated. Our results strongly support the presumable transmission of pathogens through a shared toilet seat.

Because we found a relevant concentration of SPED on a doctor's mobile phone far from the study patients' room and because mobile devices are increasingly used at the bedside, we decided to design a quasi-realistic patient care scenario that guaranteed SPED could only reach the second patient through the mobile phone. The different contamination levels found on the phone's screen and back, again indicate the translation of hand touching into SPED detection patterns. Of note, the well-known risk of pathogen transmission through stethoscopes was echoed in this experiment by a higher SPED load. Thakur et al. [27] equally found stethoscopes to transmit a surrogate 
marker and MRSA. Thus, we agree with other authors who have suggested targeted cleaning of stethoscopes $[48,49]$ and phones [50-52] before.

This study has limitations. First, the number of conducted experiments did not allow to perform comparative statistics. Our goal was to use SPED for the first time in a real-life hospital setting and outbreak situation and to test if toilet seats need indeed to be considered in the spread of VRE or other potentially multi-drug resistant enteric flora. Second, as is the case with other surrogate tracers [27], habitual disinfection products do not inactivate SPED, while thorough cleaning with detergent and water does. This precludes mimicking real-life transmission perfectly, but instead allows to trace potential transmission pathways in the absence of disinfection procedures or, as our patient experiment shows, with the flawed execution of cleaning and disinfection procedures as it is often observed in real life. Further development of the SPED technology rendering the particles sensitive to disinfection agents might be feasible. Third, the extent of the spread of SPED ultimately depends on the quantity initially applied, but as Otter et al. [12] stated, the presence of pathogens at any concentration carries a risk for a transmission. Furthermore, the interpretation of relative quantity of recovered SPED must be taken with caution, since it depends on many factors including the swabbing technique. This does, however, not interfere with the discovery of transmission pathways. Fourth, by which intermediate transmission steps SPED reach the detection sites (e.g., the doctor's keyboard or mobile phone) remains unknown. Therefore, time intervals and swabbing sites must be determined based on an initial hypothesis. Resolution can be increased by increasing the number of swabbing sites and rates as did Oelberg et al. [26], or by adding targeted evaluations as in our mobile device experiment. Fifth, being aware of an ongoing transmission experiment on their ward, HCW may have enhanced their infection prevention behaviour, e.g., use of alcohol-based handrub. The effect on spread of SPED would have been limited since SPED are not sensitive to alcohol. Moreover, this study was conducted during the SARS-CoV-2-pandemic, which has been associated with altered infection prevention behaviour $[54,55]$. Sixth, as the name suggests, surrogate markers remain a substitute and will never behave exactly equal to microorganisms.

Transmission of microorganisms is not in itself negative, as it could play an important role in establishing and maintaining protective microbiota [53]. SPED could eventually play a role to gather more corresponding insights.

\section{Conclusion}

In conclusion, SPED spread between patients through shared toilet use in a two-bed patient room, starting from a small, contaminated skin area in one patient. This finding highlighted the need for a reliable cleaning protocol, specifically as a potentially successful control element of an ongoing VRE outbreak. Intravenous pumps, mobile phones, and stethoscopes equally qualify as transmission hubs. And finally, the well-established transmission risk associated with patients' and HCWs' hands was confirmed. With this study, SPED were successfully applied in a real-life healthcare environment for the first time. As an immediate reaction to the results of this study we increased VRE outbreak control measures for common toilets and introduced wireless buzzers to alert cleaning staff of their use. Future development of the SPED tracer system could attempt to render SPED sensitive to common disinfection procedures and combine them with automated registration of human activity to increase natural fidelity.

\section{Appendix}

\section{Technical appendix}

DNA barcode sequences

DNA barcodes were ordered as single strands at a length of 65 nucleotides, with $40 \%$ GC-content, as listed in Table 3. The sequences were synthesized by Microsynth AG (Balgach, Switzerland) and shipped in dried state. Previous to annealing, the single strands were dissolved in annealing buffer (Tris $10 \mathrm{mmol} / \mathrm{L} \mathrm{pH} \mathrm{7.5-8.0,} \mathrm{EDTA}$ $1 \mathrm{mmol} / \mathrm{L}, \mathrm{NaCl} 50 \mathrm{mmol} / \mathrm{L}$ ) to a final concentration of $5 \mathrm{~g} / \mathrm{L}$. For annealing, the single strands were mixed

Table 3 DNA sequences used for SPED synthesis

\begin{tabular}{ll}
\hline Name & Sequence \\
\hline SPED-1 forward & TTATGGGCTCTAAGGATCTCTTCGTTGTCGTTAGGTTCCTGCGTTTTTCGATTCGAGGGTGAGTT \\
SPED-1 reverse & AACTCACCCTCGAATCGAAAAACGCAGGAACCTAACGACAACGAAGAGATCCTTAGAGCCCATAA \\
SPED-2 forward & TATGCGCCTTTATACTCTTATAGGTATCCTGTTGCTGGCACTTTTTTCTAGCAAAGTCTTCTCCT \\
SPED-2 reverse & AGGAGAAGACTTTGCTAGAAAAAAGTGCCAGCAACAGGATACCTATAAGAGTATAAAGGCGCATA \\
SPED-3 forward & TAGCTCGTTCATAGAATCACTTCGCCGTACTCAACGTAGTGGTTTTGTTTAGCTCAAACAGGTT \\
SPED-3 reverse & AACCTGTTTGAGCTAAACAAAAACCACTACGTTGAGTACGGCGAAGTGATTCTATGAACGAGCTA \\
\hline
\end{tabular}


together in equal parts, treated at $95{ }^{\circ} \mathrm{C}$ for $5 \mathrm{~min}$ and slowly cooled down to room temperature.

\section{SPED synthesis}

Per batch of DNA encapsulation, $4 \times 4 \mathrm{~mL}$ of silica nanoparticles $(110 \mathrm{~nm}, 50 \mathrm{mg} / \mathrm{mL}$ in isopropanol; Pinfire, Frankfurt a. M., Germany) were surface-functionalized in 4 falcon tubes. For functionalization, $40 \mu \mathrm{g}$ of $N$-trimethoxysilylpropyl- $N, N, N$-trimethylammonium chloride (TMAPS) (50 wt\% in methanol; abcr, Karlsruhe, Germany) were added, followed by $12 \mathrm{~h}$ of shaking at room temperature, at 900 rotations per minute (rpm). Next, a $2 \mathrm{~mL}$ batch of $150 \mathrm{ng} / \mu \mathrm{L}$ of corresponding annealed DNA (sequences see Table 3) was added to $200 \mathrm{~mL}$ ultrapure water (mQ; type $1,18.2 \mathrm{M} \Omega \cdot \mathrm{cm}$ at $24^{\circ} \mathrm{C}$, Milli$\mathrm{Q}^{\circledR}$; Merck, Darmstadt, Germany), followed by adding $0.4 \mathrm{~g}$ of the functionalized particles and vortexing for $10 \mathrm{~s}$. Subsequently, $4 \mu \mathrm{L}$ TMAPS were added, before vortexing and sonicating for $20 \mathrm{~s}$. Then, $62.5 \mu \mathrm{L}$ of tetraethyl orthosilicate (TEOS) ( $\geq 99.0 \%$; Sigma-Aldrich, St. Louis, Missouri, USA) were added. The mixture was shaken for $5 \mathrm{~h}$ at $600 \mathrm{rpm}$. In a further step, $10 \mathrm{~mL} \mathrm{iPrOH}$ and $5.9 \mathrm{~mL}$ TEOS were mixed with $484.1 \mathrm{~mL}$ ultrapure water and combined with the previous suspension. The batch was then stirred for 4 days at $600 \mathrm{rpm}$. Three different batches were synthesized, each labeled with its own DNA barcode.

\section{SPED characterization}

DNA loading of the SPED batches was estimated by measurement of DNA concentration in solution before and after the reaction on a photometer (NanoDrop 2000c; Thermo Fisher Scientific, Waltham, Massachusetts, US), the difference being the amount of loaded DNA. Hydrodynamic size distributions of SPED in suspension $(\sim 2 \mathrm{mg} / \mathrm{mL}$ in $\mathrm{mQ}$ water) were measured using a dispersion analyser (LUMiSizer, $470 \mathrm{~nm}$ light source; LUM GmbH, Berlin, Germany). Transmission profiles were recorded in time intervals of $5 \mathrm{~s}$, at a rotational speed of 3000-4000 rpm, for $2 \mathrm{~h}$. Statistical data analysis was performed by SEPView ${ }^{\circledR}$ software provided with the dispersion analyser. For scanning electron microscopy (SEM), SPED were prepared at a concentration of $0.1 \mathrm{mg} /$ $\mathrm{mL}$ in $\mathrm{iPrOH}$, loaded on a STEM C-grid and dried under infrared light. Imaging was performed on a NovaNanoSEM450 device (Field Electron and Ion Company, Hillsboro, Oregon, US) at a voltage of $20 \mathrm{kV}$.

\section{Recovery and processing of SPED}

In our experiments SPED were diluted in ultrapure MilliQ water (type $1,18.2 \mathrm{M} \Omega \cdot \mathrm{cm}$ at $24{ }^{\circ} \mathrm{C}$, Milli-Q ${ }^{\circledR}$; Merck, Darmstadt, Germany) to a working concentration of $1 \mathrm{mg} / \mathrm{mL}$, of which $3 \mathrm{~mL}$ were used for patient colonization. To detect SPED on skin or surfaces, a similar swabbing technique as established by Scotoni et al. [25] was applied. The swabbing technique included cotton swabs (Naturaline Wattestäbchen, Steinfels Swiss, Winterthur, Switzerland) premoistened in 20\% glycerol solution (99+\% Glycerol 1 L, VWR chemicals bvba, Leuven, Belgium; 20 vol\% in $\mathrm{mQ}$ water) that were rolled three times over a pre-defined area and then added to $2 \mathrm{~mL}$ microcentrifugation tubes (Eppendorf AG, Hamburg, Germany) pre-filled with $200 \mu \mathrm{L} \mathrm{mQ}$ water and stored at room temperature. To fit the cotton swabs in the tubes, swabs were shortened with scissors. All samples were transported to the laboratory for further processing.

\section{Quantification of SPED}

The swabs obtained at the experimental site were stored at room temperature for a maximal duration of $14 \mathrm{~h}$ before being processed. For subsequent SPED quantification, each sample was ultrasonicated for $15 \mathrm{~min}$ and briefly spun down in a minicentrifuge to clear the SPED from the cotton swab as much as possible. For the etching process $2 \mathrm{vol} \%$ of buffered oxide etch, consisting of $0.03 \mathrm{wt} \%$ ammonium hydrogen difluoride $\left(\mathrm{NH}_{4} \mathrm{FHF}\right.$, pure; Merck, Darmstadt, USA) and $0.02 \mathrm{wt} \%$ ammonium fluoride $\left(\mathrm{NH}_{4} \mathrm{~F}\right.$, puriss.; Sigma-Aldrich, St. Louis, Missouri, USA), was added to the sample liquid to release the DNA from the silica particles. All samples were ultrasonicated again for $15 \mathrm{~min}$ after adding BOE.

The suspension was then analyzed by real-time quantitative PCR (LightCycler ${ }^{\circledR}$ 96, Roche Molecular Systems, Pleasanton, USA) with $\mathrm{SYBR}^{\circledR}$ Green Master Mix (KAPA SYBR FAST qPCR master mix universal (2x, Kapa Biosystems, cat. no. KK4601)). The qPCR total reaction volume was $20 \mu \mathrm{L}$ made up of $5 \mu \mathrm{L}$ sample solution, $1 \mu \mathrm{L}$ each of $10 \mu \mathrm{M}$ forward and reverse primer stock solutions (Microysynth AG, Balgach, Switzerland, Table 4), $10 \mu \mathrm{L}$ mastermix, and $3 \mu \mathrm{L} \mathrm{mQ}$ water. The qPCR program contained a preincubation for $240 \mathrm{~s}$ at $95^{\circ} \mathrm{C}$, followed by 40 cycles of a 3-step amplification protocol $\left(2 \mathrm{~s}\right.$ at $95^{\circ} \mathrm{C}, 12 \mathrm{~s}$ at $60{ }^{\circ} \mathrm{C}, 4 \mathrm{~s}$ at $72{ }^{\circ} \mathrm{C}$ ). Technical triplicates were measured for each sample, using no-template controls as PCR negatives. Further calculations were based on qPCR cycle

\begin{tabular}{|c|c|}
\hline GM-06-S1 (SPED-1) & $\begin{array}{l}\text { Primer forward ATGGGCTCTAAGGATCTC } \\
\text { Primer reverse CTCACCCTCGAATCGAA }\end{array}$ \\
\hline GM-06-S2 (SPED-2) & $\begin{array}{l}\text { Primer forward ATGCGCCTTTATACTCTTA } \\
\text { Primer reverse GGAGAAGACTTTGCTAGAA }\end{array}$ \\
\hline GM-06-S3 (SPED-3) & $\begin{array}{l}\text { Primer forward AGCTCGTTCATAGAATCAC } \\
\text { Primer reverse ACCTGTTTGAGCTAAACAA }\end{array}$ \\
\hline
\end{tabular}


values (Cq value) provided by LightCycler96 Software standard protocol.

\section{Calculation of SPED concentration per sample}

To quantify the amount of SPED in each sample, calibration curves were measured. For each batch of SPED used in our experiments a dilution series with 5 to 6 different concentrations $\left(10^{-3}, 10^{-4} \mathrm{mg} / \mathrm{mL}\right.$, etc.) was measured to assign established particle concentrations to the according cycle value from the qPCR.

The qPCR cycle values of the dilution series were plotted against the logarithmic particle concentration (in $\mathrm{mg} /$ $\mathrm{mL}$ resulting in a calibration curve. Use of linear regression of the single log chart generates a curve in the form of $y=a x+b$ ( $y$ as the cycle value and $\mathrm{x}$ as the ln of the concentration), consequently the concentration equals $\mathrm{e}^{\mathrm{y} /}$ $\mathrm{m}-\mathrm{b}$.

The concentration of a given sample was calculated using the above formula with the respective regression parameters (Table 5). Error bars are based on the standard deviation of technical triplicates in qPCR data.

\section{Evaluation of SPED and threshold}

Prior to each experiment every sampling site was swabbed as a blank sample. The blank sample with the lowest qPCR cycle value and thus, the highest load of SPED was used as threshold for the according experiment. The cut-off value was calculated based on the qPCR cycle value plus the standard deviation of the technical triplicates. Sample concentration above threshold were considered as positive for SPED, values below as negative.

\section{Scanning electron microscopy SEM}

SPED were prepared as a suspension of $0.1 \mathrm{mg} / \mathrm{mL}$ in 2-propanol, loaded on a STEM C-grid and dried under infrared light. The samples were imaged on a NovaNanoSEM450 device (Field Electron and Ion Company, Hillsboro, Oregon, US) at a voltage of $20 \mathrm{kV}$ at 52,480x magnification (Fig. 6).

Table 5 Regression parameters for calculation of SPED concentration with the formula: $y=a x+b$ ( $y$ as the cycle value and $x$ as the In of the concentration)

\begin{tabular}{llll}
\hline Batch & a & $\mathbf{b}$ & $\begin{array}{l}\mathbf{R}^{2} \\
\text { (coefficient of } \\
\text { determination) }\end{array}$ \\
\hline SPED-1 (GM-06-S1) & -1.404 & -4.429 & 0.994 \\
SPED-2 (GM-06-S2) & -1.645 & -5.397 & 0.999 \\
SPED-3 (GM-06-S3) & -1.852 & -6.345 & 0.999 \\
\hline
\end{tabular}

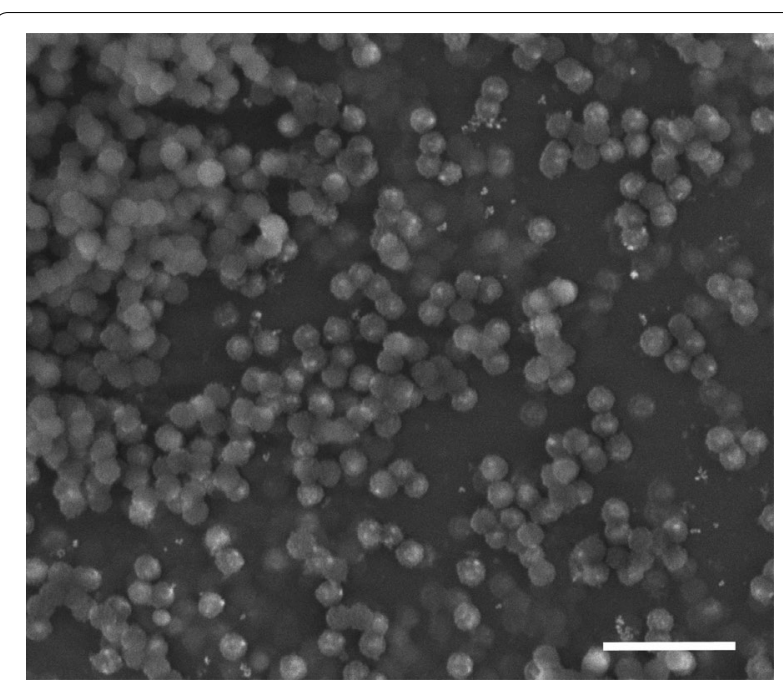

Fig. 6 Scanning electron microscopy image of dried SPED. Scale bar indicates $500 \mathrm{~nm}$

\section{Abbreviations}

aOR: Adjusted odds ratio; HCAl: Healthcare associated infections; HCW: Healthcare worker; HCWH: Healthcare worker's hands; $\mathrm{HH}$ : Hand hygiene; mQ water: Ultrapure MilliQ water (type 1, $18.2 \mathrm{M} \Omega \cdot \mathrm{cm}$ at $24^{\circ} \mathrm{C}$, Milli-Q $\mathrm{Q}^{\circledR}$; Merck, Darmstadt, Germany); MRSA: Methicillin-resistant Staphylococcus aureus; qPCR: Quantitative polymerase-chain-reaction; SPED: Silica particles with encapsulated DNA; VRE: Vancomycin-resistant enterococci.

\section{Acknowledgements}

We would like to warmly thank all volunteers, patients, nurses, and physicians who participated in this study. We also want to express our special gratitude to Manuela Scotoni for her advice, and to Sarah York who proofread our manuscript as native English speaker.

\section{Authors' contributions}

$\mathrm{CU}, \mathrm{HS}$, RNG and AML conceptualized and designed the study. JK synthesized the SPED and took an advisory role in planning the field experiments and in improving the sampling technique. AML and CU took explorative experiments in the lab, planned the field experiments, and conducted in-lab-preparations before all field experiments. CU conducted all field experiments. CU and AML analysed all samples in the laboratory gaining raw data. AML performed particle characterization, optimized the GPCR protocol, and acquired the calibration curves. CU processed the raw data. CU, AML and HS evaluated the data. CU and AML drafted and finalised the manuscript; AML supplemented the technical aspects. HS and RNG took an advisory role during manuscript revision. All authors read and approved the final manuscript.

\section{Funding}

The study did not receive dedicated funding.

\section{Availability of data and materials}

The datasets analysed during the current study are available from the corresponding author on reasonable request.

\section{Declarations}

\section{Ethics approval and consent to participate}

The Ethics Board of the Canton of Zurich reviewed the study protocol and formally waved the necessity for a full ethics review based on the Swiss Law on Research on Humans [BASEC-Nr. Req-2020-00974]. 


\section{Consent for publication \\ Not applicable.}

\section{Competing interests}

RNG declares a financial interest as a shareholder of Haelixa AG, Kemptthal, Switzerland. IP on DNA encapsulated into silica nanoparticles is licensed to Haelixa AG. All other authors have no conflicts of interest. HS reports a travel grant and speaker's honorary from AstraZeneca in 2020 and speaker honorary from agfam (non-profit) and Livinguard AG in 2021 not related to this work.

\section{Author details}

'Department of Infectious Diseases and Hospital Epidemiology, University Hospital Zurich, University of Zurich, Zurich, Switzerland. ${ }^{2}$ Department of Chemistry and Applied Biosciences, Institute for Chemical and Bioengineering, ETH Zurich, Vladimir-Prelog-Weg 1-5/10, 8093 Zurich, Switzerland. ${ }^{3}$ Department of Infectious Diseases, Bern University Hospital and University of Bern, Friedbuehlstrasse 53, 3010 Bern, Switzerland.

Received: 2 September 2021 Accepted: 6 December 2021 Published online: 10 January 2022

\section{References}

1. WHO. Report on the endemic burden of healthcare-associated infection Worldwide. World Health Organization; 2011.

2. WHO guidelines on hand hygiene in health care: First global patient safety challenge clean care is safer care. 2009.

3. O'Neill J. Antimicrobial resistance antimicrobial resistance: tackling a crisis for the health and wealth of nations. mSystems. 2014;6:e0036021.

4. Buetti N, Wassilew N, Rion V, Senn L, Gardiol C, Widmer A, et al. Emergence of vancomycin-resistant enterococci in Switzerland: a nation-wide survey. Antimicrob Resist Infect Control. 2019;8:16.

5. Thierfelder C, Keller PM, Kocher C, Gaudenz R, Hombach M, Bloemberg GV, et al. Vancomycin-resistant enterococcus. Swiss Med Wkly. 2012;142:w13540

6. Widmer AF. Vancomycin-resistant enterococci: an ongoing challenge for infection control. Swiss Med Wkly. 2012;142:w13554.

7. Pittet D, Allegranzi B, Sax H, Dharan S, Pessoa-Silva CL, Donaldson L, et al. Evidence-based model for hand transmission during patient care and the role of improved practices. Lancet Infect Dis. 2006;6(10):641-52.

8. Sax H, Allegranzi B, Uçkay I, Larson E, Boyce J, Pittet D. "My five moments for hand hygiene": a user-centred design approach to understand, train, monitor and report hand hygiene. J Hosp Infect. 2007:67(1):9-21.

9. Gould DJ, Moralejo D, Drey N, Chudleigh JH. Interventions to improve hand hygiene compliance in patient care. Cochrane Database Syst Rev. 2010;9:CD005186.

10. Clack L, Scotoni M, Wolfensberger A, Sax H. "First-person view" of pathogen transmission and hand hygiene-use of a new head-mounted video capture and coding tool. Antimicrob Resist Infect Control. 2017;6:108

11. Otter JA, Yezli S, Salkeld JA, French GL. Evidence that contaminated surfaces contribute to the transmission of hospital pathogens and an overview of strategies to address contaminated surfaces in hospital settings. Am J Infect Control. 2013;41(5 Suppl):S6-11.

12. Otter JA, Yezli S, French GL. The role played by contaminated surfaces in the transmission of nosocomial pathogens. Infect Control Hosp Epidemiol. 2011:32(7):687-99.

13. Wolfensberger A, Clack L, Kuster SP, Passerini S, Mody L, Chopra V, et al. Transfer of pathogens to and from patients, healthcare providers, and medical devices during care activity-a systematic review and meta-analysis. Infect Control Hosp Epidemiol. 2018;39(9):1093-107.

14. Ray AJ, Hoyen CK, Taub TF, Eckstein EC, Donskey CJ. Nosocomial transmission of vancomycin-resistant enterococci from surfaces. JAMA. 2002:287(11):1400-1.

15. Drees M, Snydman DR, Schmid CH, Barefoot L, Hansjosten K, Vue PM, et al. Prior environmental contamination increases the risk of acquisition of vancomycin-resistant enterococci. Clin Infect Dis. 2008;46(5):678-85.

16. Huang SS, Datta R, Platt R. Risk of acquiring antibiotic-resistant bacteria from prior room occupants. Arch Intern Med. 2006;166(18):1945-51.

17. Weber DJ, Anderson D, Rutala WA. The role of the surface environment in healthcare-associated infections. Curr Opin Infect Dis. 2013;26(4):338-44.
18. Stiller A, Salm F, Bischoff P, Gastmeier P. Relationship between hospital ward design and healthcare-associated infection rates: a systematic review and meta-analysis. Antimicrob Resist Infect Control. 2016;5:51.

19. McDonald EG, Dendukuri N, Frenette C, Lee TC. Time-series analysis of health care-associated infections in a new hospital with all private rooms. JAMA Intern Med. 2019;179(11):1501-6.

20. Duckro AN, Blom DW, Lyle EA, Weinstein RA, Hayden MK. Transfer of vancomycin-resistant enterococci via health care worker hands. Arch Intern Med. 2005:165(3):302-7.

21. Hayden MK, Blom DW, Lyle EA, Moore CG, Weinstein RA. Risk of hand or glove contamination after contact with patients colonized with vancomycin-resistant enterococcus or the colonized patients' environment. Infect Control Hosp Epidemiol. 2008;29(2):149-54.

22. Randle J, Arthur A, Vaughan N. Twenty-four-hour observational study of hospital hand hygiene compliance. J Hosp Infect. 2010;76(3):252-5.

23. Cassone M, Mantey J, Perri MB, Gibson K, Lansing B, McNamara S, et al. Environmental panels as a proxy for nursing facility patients with methicillin-resistant Staphylococcus aureus and vancomycin-resistant enterococcus colonization. Clin Infect Dis. 2018;67(6):861-8.

24. Giannini MA, Nance D, McCullers JA. Are toilet seats a vector for transmission of methicillin-resistant Staphylococcus aureus? Am J Infect Control. 2009;37(6):505-6.

25. Scotoni M, Koch J, Julian TR, Clack L, Pitol AK, Wolfensberger A, et al. Silica nanoparticles with encapsulated DNA (SPED) - a novel surrogate tracer for microbial transmission in healthcare. Antimicrob Resist Infect Control. 2020;9(1):152

26. Oelberg DG, Joyner SE, Jiang X, Laborde D, Islam MP, Pickering LK. Detection of pathogen transmission in neonatal nurseries using DNA markers as surrogate indicators. Pediatrics. 2000;105(2):311-5.

27. Thakur M, Alhmidi H, Cadnum JL, Jencson AL, Bingham J, Wilson BM, et al. Use of viral DNA surrogate markers to study routes of transmission of healthcare-associated pathogens. Infect Control Hosp Epidemiol. 2020;42:1-6.

28. Alhmidi H, Cadnum JL, Jencson AL, Gweder AA, Donskey CJ. Sharing is not always a good thing: Use of a DNA marker to investigate the potential for ward-to-ward dissemination of healthcare-associated pathogens. Infect Control Hosp Epidemiol. 2019;40(2):214-6.

29. Alhmidi H, John A, Mana TC, Koganti S, Cadnum JL, Shelton MB, et al. Evaluation of viral surrogate markers for study of pathogen dissemination during simulations of patient care. Open Forum Infect Dis. 2017;4(3):ofx128.

30. John A, Alhmidi H, Cadnum JL, Jencson AL, Donskey CJ. Contaminated portable equipment is a potential vector for dissemination of pathogens in the intensive care unit. Infect Control Hosp Epidemiol. 2017:38(10):1247-9.

31. Alhmidi H, Koganti S, Cadnum JL, Jencson AL, John A, Donskey CJ. Dissemination of a nonpathogenic viral DNA surrogate marker from hightouch surfaces in rooms of long-term care facility residents. Am J Infect Control. 2017:45(10):1165-7.

32. Koganti S, Alhmidi H, Tomas ME, Cadnum JL, Jencson A, Donskey CJ. Evaluation of hospital floors as a potential source of pathogen dissemination using a nonpathogenic virus as a surrogate marker. Infect Control Hosp Epidemiol. 2016:37(11):1374-7.

33. Tomas ME, Cadnum JL, Mana TS, Jencson AL, Koganti S, Alhmidi H, et al. Utility of a novel reflective marker visualized by flash photography for assessment of personnel contamination during removal of personal protective equipment. Infect Control Hosp Epidemiol. 2016;37(6):711-3.

34. Alhmidi H, Li DF, Cadnum JL, Haq MF, Pinto-Herrera NC, Wilson BM, et al. Use of simulations to evaluate the effectiveness of barrier precautions to prevent patient-to-patient transfer of healthcare-associated pathogens. Infect Control Hosp Epidemiol. 2020;42:1-6.

35. Alhmidi H, Koganti S, Tomas ME, Cadnum JL, Jencson A, Donskey CJ. A pilot study to assess use of fluorescent lotion in patient care simulations to illustrate pathogen dissemination and train personnel in correct use of personal protective equipment. Antimicrob Resist Infect Control. 2016:5:40.

36. Paunescu D, Puddu M, Soellner JO, Stoessel PR, Grass RN. Reversible DNA encapsulation in silica to produce ROS-resistant and heat-resistant synthetic DNA 'fossils.' Nat Protoc. 2013;8(12):2440-8.

37. Grass RN, Schälchli J, Paunescu D, Soellner JOB, Kaegi R, Stark WJ. Tracking trace amounts of submicrometer silica particles in wastewaters and 
activated sludge using silica-encapsulated DNA barcodes. Environ Sci Technol Lett. 2014;1 (12):484-9.

38. Bloch MS, Paunescu D, Stoessel PR, Mora CA, Stark WJ, Grass RN. Labeling milk along its production chain with DNA encapsulated in silica. J Agric Food Chem. 2014;62(43):10615-20.

39. Mora CA, Paunescu D, Grass RN, Stark WJ. Silica particles with encapsulated DNA as trophic tracers. Mol Ecol Resour. 2015;15(2):231-41.

40. Mikutis G, Deuber CA, Schmid L, Kittila A, Lobsiger N, Puddu M, et al. Silica-encapsulated DNA-based tracers for aquifer characterization. Environ Sci Technol. 2018;52(21):12142-52.

41. Croissant JG, Fatieiev Y, Khashab NM. Degradability and clearance of silicon, organosilica, silsesquioxane, silica mixed oxide, and mesoporous silica nanoparticles. Adv Mater. 2017;29(9):1604634.

42. Huslage K, Rutala WA, Sickbert-Bennett E, Weber DJ. A quantitative approach to defining "high-touch" surfaces in hospitals. Infect Control Hosp Epidemiol. 2010;31 (8):850-3.

43. Drankiewicz D, Dundes L. Handwashing among female college students. Am J Infect Control. 2003;31(2):67-71.

44. Shams AM, Rose LJ, Edwards JR, Cali S, Harris AD, Jacob JT, et al. Assessment of the overall and multidrug-resistant organism bioburden on environmental surfaces in healthcare facilities. Infect Control Hosp Epidemiol. 2016;37(12):1426-32.

45. Eckstein BC, Adams DA, Eckstein EC, Rao A, Sethi AK, Yadavalli GK, et al. Reduction of clostridium difficile and vancomycin-resistant enterococcus contamination of environmental surfaces after an intervention to improve cleaning methods. BMC Infect Dis. 2007;7:61.

46. Pearman JW. Lowbury Lecture: the Western Australian experience with vancomycin-resistant enterococci-from disaster to ongoing control. J Hosp Infect. 2004;63:14-26.

47. Vuichard-Gysin D, Schlegel MT, Senn N, Marschall L, Blanc J, Buetti DS, Egli N, A, Kuster SK, Balmelli A, Sommerstein C, Nartey R, Masserey Spicher L, Gardiol V, C, Widmer AF, Harbarth S. Eindämmung der Verbreitung von Vancomycin-resistenten Enterokokken (VRE) in der Schweiz: Aktualisierung der nationalen Empfehlungen. VRE task force, on behalf of Swissnoso; 2019.

48. Longtin Y, Schneider A, Tschopp C, Renzi G, Gayet-Ageron A, Schrenzel J, et al. Contamination of stethoscopes and physicians' hands after a physical examination. Mayo Clin Proc. 2014;89(3):291-9.

49. O'Flaherty N, Fenelon L. The stethoscope and healthcare-associated infection: a snake in the grass or innocent bystander? J Hosp Infect. 2015;91(1):1-7.

50. Brady RRW, Wasson A, Stirling I, McAllister C, Damani NN. Is your phone bugged? The incidence of bacteria known to cause nosocomial infection on healthcare workers' mobile phones. J Hosp Infect. 2006;62(1):123-5.

51. Simmonds R, Lee $D$, Hayhurst E. Mobile phones as fomites for potential pathogens in hospitals: microbiome analysis reveals hidden contaminants. J Hosp Infect. 2020;104(2):207-13.

52. Martina PF, Martinez M, Centeno CK, Von Specht M, Ferreras J. Dangerous passengers: multidrug-resistant bacteria on hands and mobile phones. J Prev Med Hyg. 2019;60(4):E293-9.

53. Widmer FC, Frei R, Romanyuk A, Tschudin Sutter S, Widmer AF. Overall bioburden by total colony count does not predict the presence of pathogens with high clinical relevance in hospital and community environments. J Hosp Infect. 2019;101 (2):240-4.

54. Houghton C, Meskell P, Delaney H, Smalle M, Glenton C, Booth A, et al. Barriers and facilitators to healthcare workers' adherence with infection prevention and control (IPC) guidelines for respiratory infectious diseases: a rapid qualitative evidence synthesis. Cochrane Database Syst Rev. 2020;4:CD013582.

55. Israel S, Harpaz K, Radvogin E, Schwartz C, Gross I, Mazeh H, et al. Dramatically improved hand hygiene performance rates at time of coronavirus pandemic. Clin Microbiol Infect. 2020;26(11):1566-8.

\section{Publisher's Note}

Springer Nature remains neutral with regard to jurisdictional claims in published maps and institutional affiliations.

Ready to submit your research? Choose BMC and benefit from:

- fast, convenient online submission

- thorough peer review by experienced researchers in your field

- rapid publication on acceptance

- support for research data, including large and complex data types

- gold Open Access which fosters wider collaboration and increased citations

- maximum visibility for your research: over 100M website views per year

At BMC, research is always in progress.

Learn more biomedcentral.com/submissions 